\title{
Diversity of genomic electropherotypes of naturally occurring equine herpesvirus 1 isolates in Argentina
}

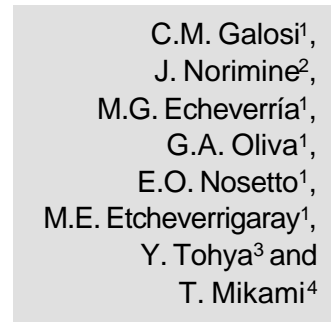

\author{
${ }^{1}$ Area of Virology, Faculty of Veterinary Sciences, National University of La Plata, \\ La Plata, Argentina \\ ${ }^{2}$ Department of Animal Science, University of Illinois, Urbana, IL, USA \\ ${ }^{3}$ Department of Veterinary Microbiology, Faculty of Agriculture, Kagoshima University, \\ Kagoshima, Japan \\ ${ }^{4}$ Department of Veterinary Microbiology, Faculty of Agriculture, University of Tokyo, \\ Tokyo, Japan
}

\section{Correspondence \\ M.E. Etcheverrigaray \\ Area of Virology \\ Faculty of Veterinary Sciences \\ National University of La Plata \\ 60 y 118,1900 La Plata \\ Argentina \\ Fax: 54-21-253276}

Research supported in part by JICA (Japan International Cooperation Agency). C.M. Galosi is a career member of Scientific Research Commission, (ClC), Buenos Aires Province; M.G. Echeverria and E.O. Nosetto are career members of National Research Council (CONICET), Argentina.

Received August 13, 1997 Accepted March 4, 1998

\section{Abstract}

The genomes of 10 equine herpesvirus 1 (EHV-1) strains isolated in Argentina from 1979 to 1991, and a Japanese HH1 reference strain were compared by restriction endonuclease analysis. Two restriction enzymes, BamHI and BglII, were used and analysis of the electropherotypes did not show significant differences among isolates obtained

Key words

- Argentina

- Electropherotypes

- Equine herpesvirus from horses with different clinical signs. This suggests that the EHV1 isolates studied, which circulated in Argentina for more than 10 years, belong to a single genotype.

Equine herpesviruses 1 and 4 (EHV-1 and EHV-4) and asinine herpesvirus 3 are related alphaherpesviruses infecting members of the family equidae (1). EHV-1 (equine abortion virus) has long been causally implicated in the occurrence of abortion, respiratory disease, neonatal deaths and neurological disorders in horses. Infection by these viruses is a serious economic problem in the horse industry worldwide, especially on breeding farms $(2,3)$. In attempts to prevent EHV-1 infection, both inactivated and attenuated vaccines have been used in several countries (4). Only the use of inactivated vaccines has been permitted in Argentina since 1982 and no earlier information about EHV vaccines is available. The first isolation of EHV-1 in Argentina occurred in 1979 (5). Since then, 14 viral isolates have been obtained, mainly from aborted fetuses, al- though one of them (LP isolate) was obtained from a horse with respiratory symptoms (6), one from a horse with neonatal disease (OR1) and one (LBLJ) was recovered from an aborted fetus on a farm where the horses showed neurological clinical signs.

It has not been possible to establish any relationship between clinical signs in horses and genomic characteristics of EHV-1 $(7,8)$. It is generally understood that a single EHV1 genotype induces different clinical signs depending on the immune condition of the host animals. At least two electropherotypes of EHV-1 (1P and 1B) have been detected (2). The purpose of the present investigation was to detect possible differences in genomic types among EHV-1 strains isolated in Argentina by restriction endonuclease (RE) analysis (9-13).

A total of ten EHV-1 isolates from our 
Figure 1 - Restriction fragment obtained with BamHI of $10 \mathrm{EHV}$ 1 strains isolated in Argentina from 1979 to 1991. M: Molecular weight marker fragments ( $\lambda$ DNA Hindll digested) are reported as kilobases. Fragment nomenclature is shown on the right according to the report for the $\mathrm{HH} 1$ strain (4).
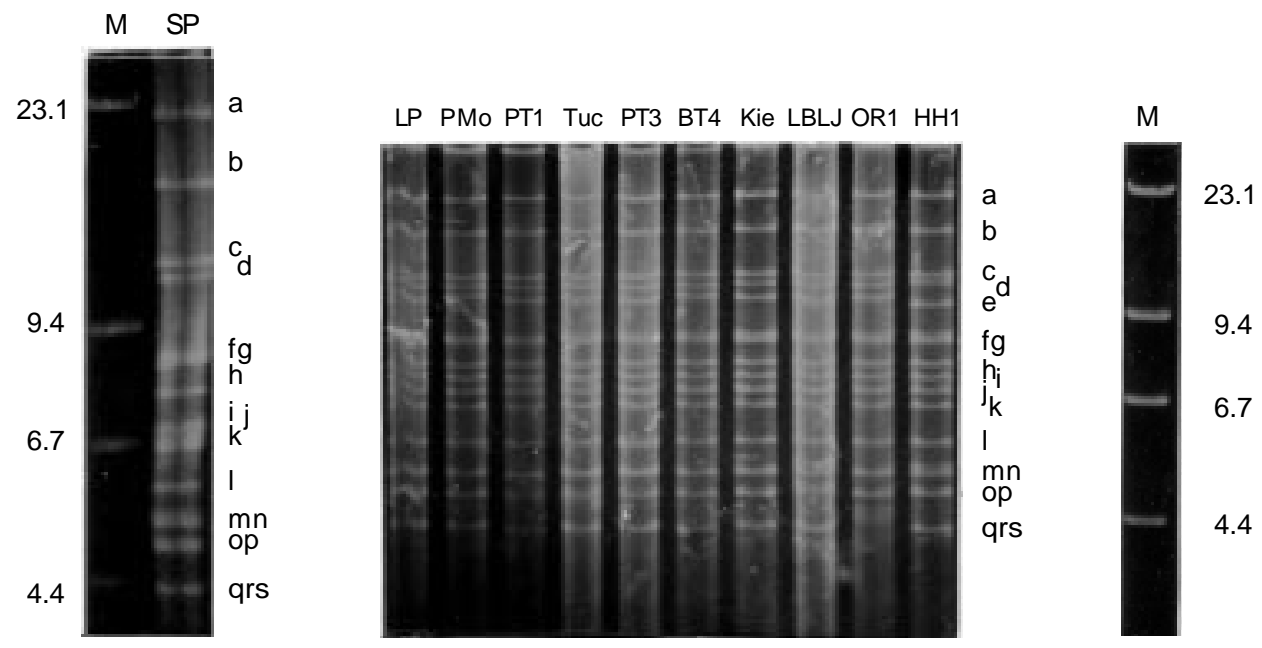

laboratory were used. Isolates SP and LP were obtained by primary tissue culture of equine fetal kidney (EFK), and the other isolates (PMo, PT1, Tuc, PT3, BT4, Kie, LBLJ, and OR1) were obtained from RK13 cells. The SP isolate was passed through different non-equine cells 62 times, while the LP and PMo isolates were passed through RK13 cells 18 times. The Japanese strain HH1 was used as the reference strain (14). All viral isolates were plaque purified using EFK cells. Cells were grown in Eagle's minimum essential medium (Nissui, Tokyo) containing $10 \%$ heat-inactivated fetal calf serum. For RE analysis, total DNA from EFK cells infected with each EHV-1 isolate was used. The total DNA was prepared as described by Echeverría et al. (15), and $1.5 \mu \mathrm{g}$ of DNA from each virus was digested with $B a m \mathrm{HI}$ and $B g l \mathrm{II}$ and separated by electrophoresis in $0.7 \%$ agarose gel in Tris-acetate buffer (40 mM Tris-acetate, $1 \mathrm{mM}$ EDTA, $\mathrm{pH} \mathrm{8.0)}$ at $20 \mathrm{~V}$ for $16 \mathrm{~h}$, stained with ethidium bromide $(1 \mu \mathrm{g} / \mathrm{ml})$ and visualized with a UV illuminator.

Figure 1 shows the RE cleavage patterns with BamHI. The SP isolate can be differentiated from the other Argentinian isolates and from the Japanese reference strain $\mathrm{HH} 1$ by the mobility of the group of fragments "h", "i", "j" and "k", and by the lack of fragment "e". The mobility of fragment "e" differed between the Japanese HH1 strain and the isolates from Argentina. The LBLJ isolate has fragments of the same mobility as the HH1 " $m$ " and " $n$ " fragments, and shows slight differences in the mobility of the group of fragments "o" and "p" with respect to the other isolates. Fragments "q", "r", and "s" show decreased mobility in the OR1 isolate.

The $B g l$ II RE patterns (Figure 2) showed that the SP isolate was distinguishable from the others by the group of fragments " $b$ ", "c" and "d". BT4, Kie and OR1 isolates showed slightly different mobilities for fragments "k", "l" and "m", while the same fragments in the HH1 strain migrated faster than in the other strains. In addition, the PT3 isolate is also different, since a band is clearly visible between the " $\mathrm{j}$ " and " $\mathrm{k}$ " fragments.

No difference in electropherotype was observed between DNA obtained directly from seed stock and DNA extracted from plaque purified virus. This is in contrast to the data reported by Allen et al. (16). Only the SP isolate showed a restriction pattern alteration consistent with a loss of specific cleavage sites as shown in Figure 1. This difference may be due, in part, to the effects of the high passage level of this isolate through heterologous cell cultures (17). Some viral isolates showed small mobility shifts of 

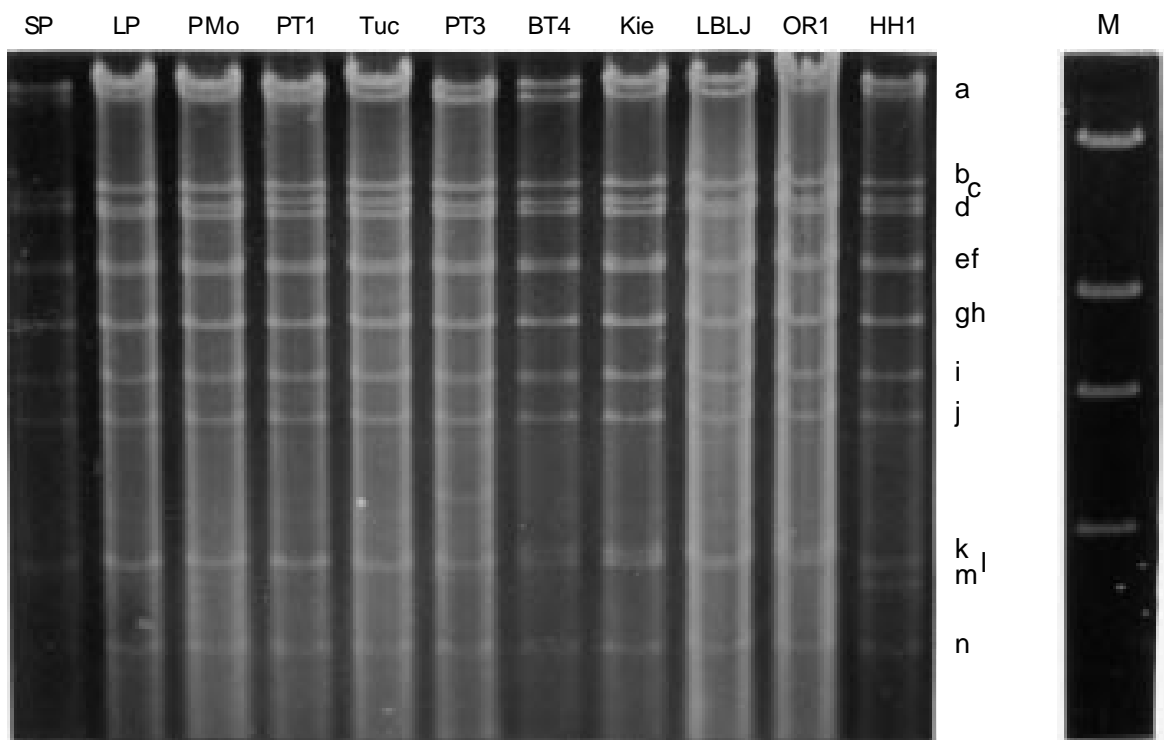

Figure 2 - Restriction fragment obtained with $B g / l$ from $10 \mathrm{EHV}$ 1 strains isolated in Argentina from 1979 to 1991. M: Molecular weight marker fragments ( $\lambda$ DNA Hindlll digested) are reported as kilobases. Fragment nomenclature is shown on the right according to the report for the $\mathrm{HH} 1$ strain (4).

the DNA fragments, but the differences among them were generally not significant.

In this study, we were not able to find significant differences in RE fragment patterns among isolates obtained from horses with different clinical signs, suggesting that the viral strains belong to a single genotype. The BamHI pattern seemed to be related to that of EHV-1 type 1P reported by Allen et al. (9), and none resembled the $1 \mathrm{~B}$ variant. We did not detect genomic fragments derived from recombination between attenuated vaccines and wild type virus, in contrast to the data reported by Palfi and Christensen (8) and Meyer et al. $(17,18)$. Similar to the results of Kirisawa et al. (4), no variability in the Bam HI "g" fragment of Argentinian EHV1 isolates was detected, indicating that this fragment is highly stable. Thus, the different clinical signs produced by the investigated viruses might be due to the different host immune response and they should not be related to the virus genotype.

This is the first molecular epidemiological investigation of Argentinian isolates of EHV-1. The reason why the DNA genomes of these field isolates show minor electropherotype differences is yet to be determined. It also remains to be shown whether there is a relationship between these alterations and variations in the antigenicity and pathogenicity of EHV-1 isolates.

Our results were obtained with a small number of EHV-1 isolates which were studied by restriction digestion with only two enzymes. Therefore, they may not accurately account for the genetic variability that these viruses may undergo. However, the lack of significant differences in restriction patterns over a period of approximately one decade among most of the EHV-1 isolates suggests that this virus has not shown a significant amount of genetic diversity in Argentina recently. 


\section{References}

1. Roizmann B, Desrosiers RC, Fleckenstein B, Lopez C, Minson AC \& Studdert MJ (1992). The family Herpesviridae: an update. Archives of Virology, 123: 425-449.

2. Allen GP \& Bryans JT (1986). Molecular epizootiology, pathogenesis and prophylaxis of equine herpesvirus-1 infections. Progress in Veterinary Microbiology and Immunology, 2: 78-144.

3. Chowdhury $\mathrm{SI}$, Kubin $\mathrm{G}$ \& Ludwig $\mathrm{H}$ (1986). Equine herpesvirus type 1 (EHV-1) induced abortions and paralysis in a Lipizzaner stud: a contribution to the classification of equine herpesviruses. $A r$ chives of Virology, 90: 273-288.

4. Kirisawa R, Ui S, Takahashi A, Kawakami $Y$ \& Iwai H (1994). Comparison of the genomes of attenuated equine herpesvirus-1 strains with their parent virulent strain. Virology, 200: 651-660.

5. Etcheverrigaray ME, Oliva GA, Gonzalez ET, Nosetto EO \& Martin AA (1982). Comportamiento de una cepa de HVE-1 aislada de un feto abortado. Revista Militar de Veterinária, 30: 138-139.

6. Galosi CM, Nosetto EO, Gimeno EJ, Gomez Dunn C, Etcheverrigaray ME \& Ando $Y$ (1989). Equine herpesvirus 1 (EHV-1): characterisation of a viral strain isolated from equine plasma in Argentina. Revue Scientifique et Technique O.I.E. (Office International des Epizooties), 8: 117-122.

7. Allen GP, Yeargan MR, Turtinen LW \&
Bryans JT (1985). A new field strain of equine abortion virus (equine herpesvirus-1) among Kentucky horses. American Journal of Veterinary Research, 46: 138140.

8. Palfi V \& Christensen LS (1995). Analysis of restriction fragment patterns (RFPs) and pathogenicity in baby mice of equine herpesvirus 1 and 4 (EHV-1 and EHV-4) strains circulating in Danish horses. Veterinary Microbiology, 47: 199-204.

9. Allen GP, Yeargan MS, Turtinen MS, Bryans JT \& McCollum WH (1983). Molecular epizootiologic studies of equine herpesvirus- 1 by restriction endonuclease fingerprinting of viral DNA. American Journal of Veterinary Research, 44: 263-271.

10. Engels M, Nowotny N, Metzler AE, Wyler R \& Burki $F$ (1986). Genomic and antigenic comparison of an equine herpesvirus-1 (EHV-1) isolate from the 1983 Lippizan abortion storm with EHV-1 reference strains. Microbiologica, 9: 221-234.

11. Sabine M, Robertson GR \& Whalley JM (1981). Differentiation of sub-types of equine herpesvirus 1 by restriction endonuclease analysis. Australian Veterinary Journal, 57: 148-149.

12. Studdert MJ, Fitzpatrick DR, Browning GF, Cullinae AA \& Whalley JM (1986). Equine herpesvirus genomes: heterogeneity of naturally occurring type 4 isolates and of a type 1 isolate after heterologous cell passage. Archives of Virology, 91:
375-381.

13. Whalley JM, Robertson GR \& Davison AJ (1981). Analysis of the genome of equine herpes virus type 1: arrangements of the cleavage sites for restriction endonucleases EcoRI, Bg/lI and BamHI. Journal of General Virology, 57: 307-323.

14. Kawakami $Y$ (1993). The genomic diversity among equine herpesvirus-1 strains isolated in Japan. Archives of Virology, 129: 11-22.

15. Echeverría MG, Norimine J, Galosi CM Oliva GA, Etcheverrigaray M, Nosetto EO, Tohya Y \& Mikami T (1994). The genotype of Aujeszky's disease viruses isolated in Argentina. Journal of Veterinary Medical Sciences, 56: 985-987.

16. Allen GP, Yeargan MR \& Bryans JT (1983). Alteration in the equine herpesvirus $1 \mathrm{ge}$ nome after in vitro and in vivo virus passage. Infection and Immunity, 40: 436439.

17. Meyer H, Hubert PH \& Eichhorn W (1987). Changes in restriction enzyme pattern of the equine herpesvirus type 1 (EHV-1) strain RacH DNA during attenuation. Journal of Veterinary Medicine B, 34: 310313.

18. Meyer $\mathrm{H}$, Hubert $\mathrm{PH}$, Schwend $\mathrm{C}$ \& Eichhorn W (1992). Rapid identification and differentiation of the vaccine strain RacH from EHV-1 field isolates using a non-radioactive DNA probe. Veterinary Microbiology, 30: 13-20. 